\title{
Ocean Wave-Structure Interaction of Two Wave Energy Converters in Malaysian Water
}

\author{
Ng ChengYee ${ }^{1}$, Tuhaijan Siti Nor Adha ${ }^{1 *}$, Velluruzhathil John Kurian², and Lim Wai Loon ${ }^{3}$ \\ ${ }^{1}$ Civil and Environmental Engineering Department, Universiti Teknologi PETRONAS, Malaysia \\ ${ }^{2}$ Dean of Research \& Development, Providence College of Engineering, India \\ ${ }^{3}$ TechnipFMC, Malaysia
}

\begin{abstract}
Due to rapid urbanization and industrialization, the consumption of electricity in the world is expected to increase, thus leads to the fast development of the renewable energy industry. In 2016, 24.5\% of the electricity is produced by renewable energy. There are several types of renewable energy, e.g. solar, wind, and ocean wave. The ocean wave energy is identified to have the greatest potential for electricity generation. There are various types of wave energy converter (WEC) that have been designed for harnessing the wave energy, e.g. the oscillating water column, salter duck, point absorber, water dagon etc. Due to the smaller dimension, the point absorber is the most suitable WEC to be deployed in an array configuration, whereby each isolated WEC interacts and alters the vicinity of the wave formation by absorbing, radiating, and diffracting the wave. Subsequently, the wave interference will also affect the WEC's performance. The objective of the present study is to investigate the optimum separation distance, $d$, that would resulting to an optimum performance between two WECs in an array configuration using a computational fluid dynamics (CFD) software. The analysis considered an isolated WEC and two WECs, i.e. the heaving point absorbers with three point catenary mooring lines. The influence of the separation distance towards diffraction and response amplitude operator (RAO) of an array of two WECs was evaluated. The optimum production of the wave energy by the heaving point absorber is observed to be highly dependant on the relative heave motion of the two WECs [1]. In the present study, it shows that the optimum distance between two WECs in an array configuration is $20 \mathrm{~m}$, whereby the maximum heave RAO were identified.
\end{abstract}

\section{Introduction}

The main energy source in Malaysia is still depending on fossil fuels even though the oil reserves have been depleted [2]. As for the current production rates, the global reserves of crude oil and natural gas are estimated to last for the next 41.8 until 60.3 years [3]. According to the International Energy Agency (IEA), by 2030, the global energy consumption will increase by 53\%. In 2016, a total of high peak electricity demand of $17,175 \mathrm{MW}$ was recorded by Tenaga National Berhad during the dry and hot season. The total installed capacity in Malaysia was 25,258 MW including all renewable energy

\footnotetext{
*Corresponding author: siti.nor_g03242@utp.edu.my
} 
sources. It is expected that the electrical energy consumption in Malaysia will be doubled upon reaching 2020 [4]. Thus, the seeking of renewable energy has become the government's agenda to reduce the $\mathrm{CO}_{2}$ emission.

By definition, renewable energy is an energy source that will not be depleted and can be replenished by nature [5]. The renewable energy resources are wind power, wave power, tidal power, solar energy, hydropower, geothermal, biofuel, and biomass. Solar and wind energies are often used as the renewable sources. In fact, solar photovoltaic power system is very suitable to be deployed in commercial and housing area [6]. Besides, there are lots of development regarding offshore wind farms. According to European Wind Energy Association (EWEA) [7], Europe has accumulated a total of 3230 wind turbines with the capacity of producing 11027.3MW at the end of 2015.

Ocean energy is one of the greatest potentials for electricity generation as it has the highest energy density among the renewable energy sources. Generally, the ocean energy comes from four distinct sources, i.e. the waves (transfer of kinetic energy in ocean waves), the tidal power (transfer of kinetic energy of tidal currents and high tides), the ocean thermal energy (extraction of energy from heat exchange processes between warm surface waters and cold seawater from deeper depths), and the ocean osmotic energy (extraction of energy due to the pressure difference between saline and freshwater). In the context of geographic, Malaysia is surrounded by long sea coastline and hence it has the potential to harness the ocean wave energy [2]. However, there are some challenges for the implementation of the ocean renewable energy in Malaysia, e.g. manufacturability, installation of WEC, operability of WEC and cost.

Ocean wave energy has several advantages, in which it has the highest energy density among the renewable energy sources. In addition to that, it is a clean energy as it has limited negative environmental impact as compared to the offshore wind farm, where the noise from the pile driving of offshore wind turbine during construction causes disturbance to the marine animals [8]. Also, ocean wave is different than another type of wave, e.g. electromagnetic wave, due to its longer wavelength, where it has the ability to travel in a long distance with a little energy loss [9].

Today, there are more than fifty different types of WEC that have been designed and proposed [10]. Generally, WEC can be categorized as the heaving devices, pitching devices, overtopping devices, and water oscillating. Among all the WEC, the point absorber WEC (heaving device) is the simplest yet robust device as compared to the other type of devices. It consists of floating body and buoy to capture the wave energy through the heave motion [11]. Since ocean waves apply large forces at low velocity, this type of device is well suited to harness the wave energy in these conditions. Besides, the smaller dimension of point absorber also makes it easier to be deployed in arrays where multiple devices are installed in the ocean with various water depths. This feature allows the system ideal to configure in relatively close proximity to increase the overall power output. However, the placement of the WECs in an array presents a challenge. In an array, each isolated WEC interacts and alters the vicinity wave formation by absorbing, radiating and diffracting the wave. Subsequently, this will affect the WEC's performance. Hence, it is very important to determine the optimum distance between the WECs.

\subsection{Array effect of WEC}

The WEC absorbs a certain amount of wave energy and converts the wave energy into the electrical energy through a power take off system. As WEC deploys in an array, the total available wave power reduces for other WEC located nearby. Therefore, the total power from an array of WEC will be less than the isolated WEC [11]. This wave interference phenomena is known as the 'park effect'. As shown in Figure 1, the wave interference of 
the WEC is generating around the structure as subjected to wave. Due to this, the response of the WEC at the first row of the array configuration will be different with and without another row of WEC at the behind row.

The main interaction effect on two interacting cylinders appears to happen at the first row of WEC [12]. This occurrence can be explained based on Figure 2. As the wave impact on the front WEC, the WEC is set into motion to absorb the energy from incoming wave. The motion of WEC gives rise to a radiated wave. After that, both the incident wave and radiated waves impact on the second WEC. Therefore, the response of this WEC depends on the motion of the first WEC. The second WEC also radiates wave and affects the first WEC by altering its response to the incoming waves.

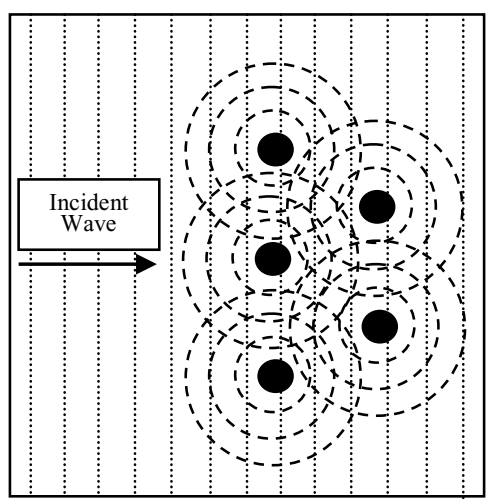

Fig. 1. Park Effect of the WEC. Adapted from Ref. [11]

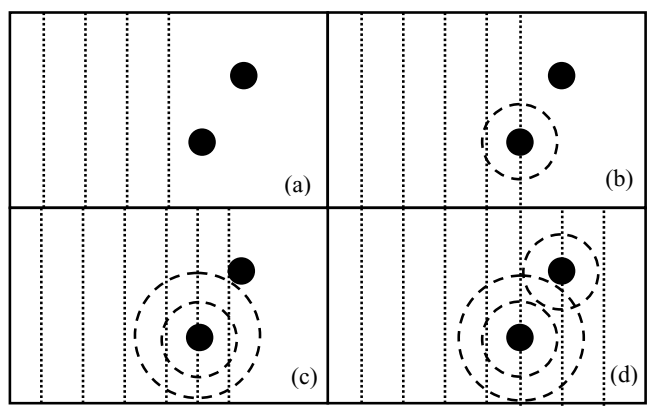

Fig. 2. Wave interference on an array of two WEC. Adapted from Ref. [12]

In this study, the main objective is to investigate the optimum separation distance, $d$, that would resulting to an optimum performance between two WECs in an array configuration using a computational fluid dynamics (CFD) software by considering the diffraction force and heave RAO values.

\section{Methodology}

In order to fulfill the objective, a simulation investigation using a CFD software has been conducted to determine the optimum separation distance between two WECs. The general sequence of operations in the simulation includes the geometry modeling (structure and mooring line), the parameter input, the simulation, and the computation of the results. The details of the simulation are explained below. 


\subsection{Geometry modeling}

The geometry of the WEC elements was defined by using a modelling software provided in the CFD software. This solid geometry was required as an input for the simulation work. The geometry modeling of the WEC was designed by referring to the Ocean Powerbuoy Technology (OBT) [13]. The model consisted of three parts, i.e. the base, spar and float as shown in Figure 3. The dimension of the device is presented in Table 1. As the WEC has been modeled, the static water level or the free surface condition was defined by dividing the model into two parts, i.e. the superstructure and the substructure.

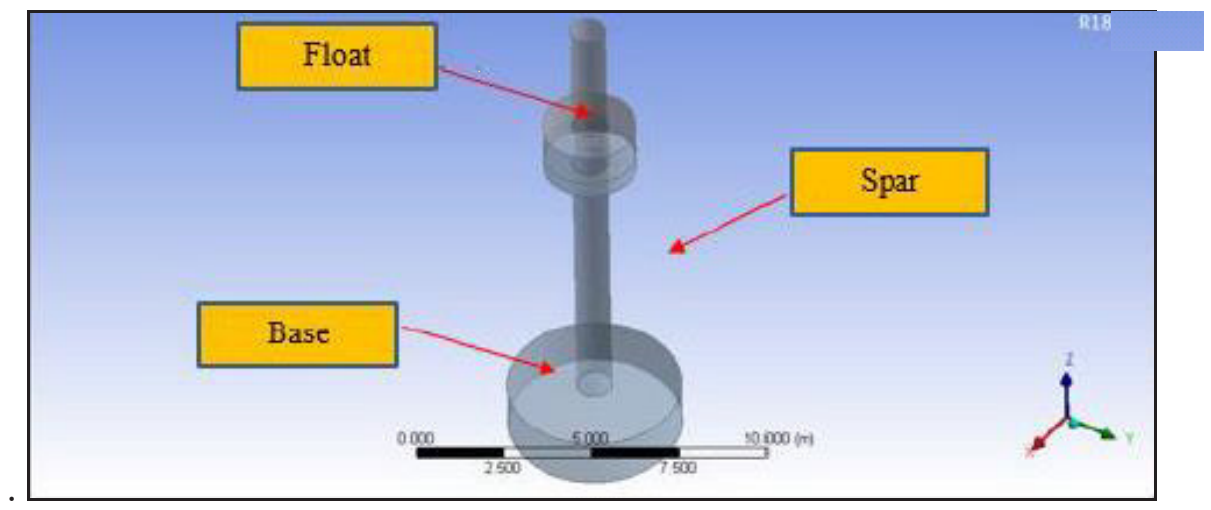

Fig. 3. Structure modeling of the WEC

Table 1. Dimension of the WEC

\begin{tabular}{|c|c|}
\hline Description & Dimension (m) \\
\hline Height & 14.3 \\
\hline Draft & 10.8 \\
\hline Spar diameter & 1.0 \\
\hline Base diameter & 2.7 \\
\hline
\end{tabular}

\subsection{Parameter input}

\subsubsection{Mooring configuration}

The mooring configuration was defined as a linear elastic cable which consisted of threepoint catenary mooring system. During the simulation, the parameters of the mooring line such as the stiffness and unstreched length were defined concurrently. The arrangement of the WEC and the three-point catenary mooring system in an array configuration is shown in Figure 4.

\subsubsection{Environmental condition}

In this study, the metocean data was adopted using Samarang field in SABAH, owing that the significant wave height and the wave period were found to be the highest as compared to the other fields in Malaysian water. This location is having a water depth of $50 \mathrm{~m}$, where 
this is a very important parameter which will affect the power output of the WEC device. The significant wave height in Samarang location is $3.7 \mathrm{~m}$ with an associated wave period of $9.4 \mathrm{~s}$.

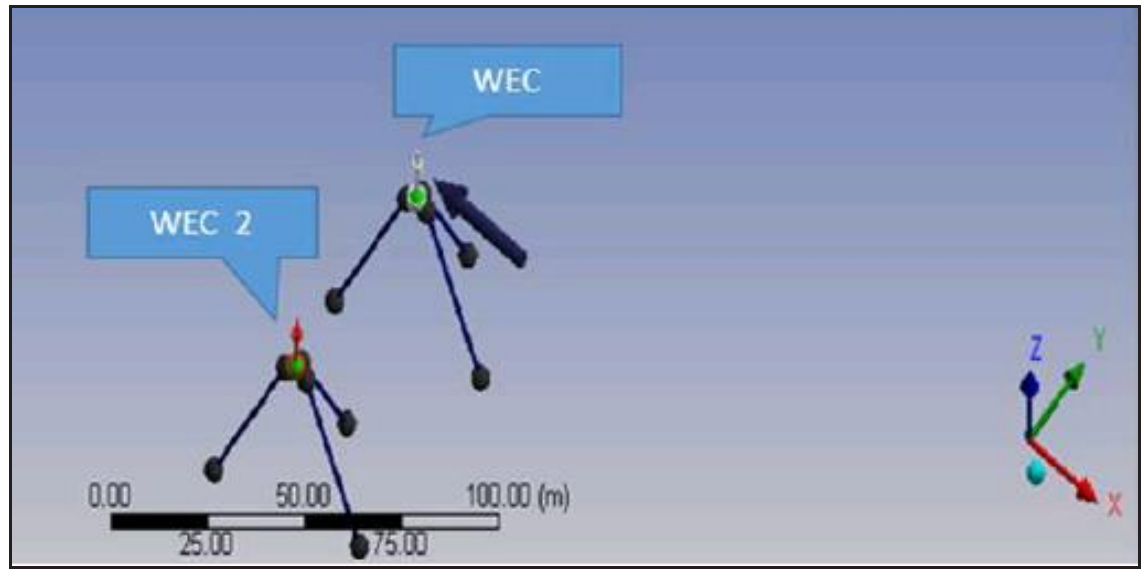

Fig. 4. The WEC and mooring line arrangement

\subsubsection{Mesh generation}

In producing an accurate result, the mesh generation is one of the important steps in the simulation process. Generally, a smaller mesh size would be preferred. An optimum mesh profile can efficiently play an important role in reducing the reflection effect caused at the outer boundaries.

\subsection{Simulation}

The simulation was carried out under an irregular long-crested wave. The wave spectrum defined in this project was based on Pierson Moskowitz provided in the CFD software.

$$
S(f)=\frac{a g^{2}}{(2 \pi)^{4} f^{4}} \exp \left[-1.25\left(\frac{f_{b}}{f}\right)^{4}\right]
$$

Where $\alpha=0.0081, f_{0}=\frac{1}{T_{p}}$, and $g=9.80665 \mathrm{~m} / \mathrm{s} 2$.

The spectrum was covered by frequencies ranging between 0.015 to $0.290 \mathrm{~Hz}$. The simulation was performed on an isolated WEC and two WECs in an array configuration subjected to an irregular long-crested wave propagating from $180^{\circ}$ direction. There were five different simulation cases were considered by varying the separation distance between the two WECs as shown in Table 2. 
Table 2. Simulation cases based on separation distance

\begin{tabular}{|c|c|}
\hline Case & Separation Distance, $\boldsymbol{d}(\mathbf{m})$ \\
\hline 1 & 0 (Individual WEC) \\
\hline 2 & 10 \\
\hline 3 & 15 \\
\hline 4 & 20 \\
\hline 5 & 25 \\
\hline
\end{tabular}

\section{Results and discussion}

In this paper, the effect of the separation distance of two WECs on the diffraction and heave RAO are presented and elaborated. Figure 5 shows the effect of the separation distance on the wave diffraction around an isolated WEC and an array of two WECs. The result shows the peak diffraction force occurs at the frequency of $0.17 \mathrm{~Hz}$ and the values are reducing at the lower and higher frequency regions. At $10 \mathrm{~m}$ of separation distance, the peak diffraction force is found to be the greatest. This is due to the diameter of the structures, which relatively close with each other, is larger as compared to the wavelength, that causes diffraction effect when subjected to the heading wave [14]. As the distance is further increased up to 20 and $25 \mathrm{~m}$, the diffraction forces are observed to be reducing, as the behaviour of the wave diffraction around the WECs are acting as same as isolated structure's. The consideration of the optimum separation distance due to the diffracted wave in an array leads to the sufficient increase in the energy absorbtion and reduction of the masking effect has been proven by Borgarino et. al [15].

Figure 6 presents the effect of separation distance on the heave RAO values. The amount of wave energy converted to electrical energy is greatly dependent on the heave motion of the WEC, thus, the higher heave RAO leads to the better performance of WEC [16]. The graph shows that the highest value of heave RAO of $1.45 \mathrm{~m} / \mathrm{m}$ occurs at the wave frequency $0.065 \mathrm{~Hz}$. It is observed for $10 \mathrm{~m}$ separation distance between two WECs, the RAO is $1.3 \mathrm{~m} / \mathrm{m}$ and increased to $1.7 \mathrm{~m} / \mathrm{m}$ when the separation distance is $15 \mathrm{~m}$. In addition, the highest RAO value of $1.8 \mathrm{~m} / \mathrm{m}$ is recorded when the separation distance is $20 \mathrm{~m}$. However, for the separation distance of $25 \mathrm{~m}$, the heave RAO value is $1.45 \mathrm{~m} / \mathrm{m}$, as same as the RAO value for isolated WEC. This indicates that at the separation distance of $25 \mathrm{~m}$, both WECs behave like the isolated WEC. This finding is agreed by Wang et. al. [16], stated that the level of hydrodynamic interaction of WEC will influence its efficiency and performance. The performance improvement caused by the interaction will diminish with increasing WEC's separation distance.

Hence, in the present study, it is found that by considering the heave RAO, the optimum separation distance is $20 \mathrm{~m}$. The heaving motion of the WEC is maximised at this distance, thus increasing the absorbed wave energy. Meanwhile, the diffraction force is found to be highest at $10 \mathrm{~m}$ distance. The consideration of this distance might be underestimated due to the destructive effect of the incoming wave that compensate each other, particularly leads to a smaller impact of the wave interactions on the absorbed energy [17]. 


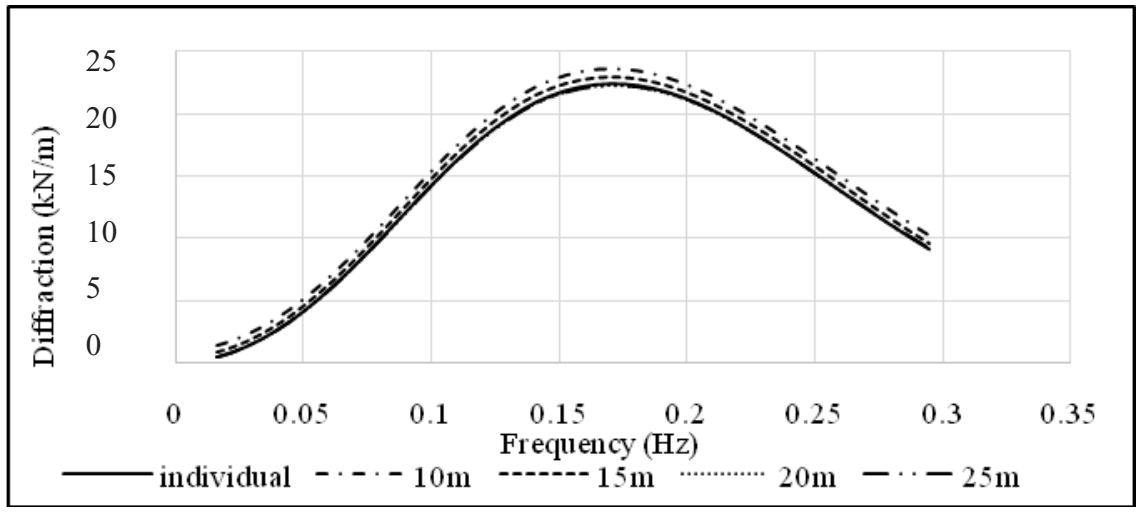

Fig. 5. Diffraction vs wave frequency

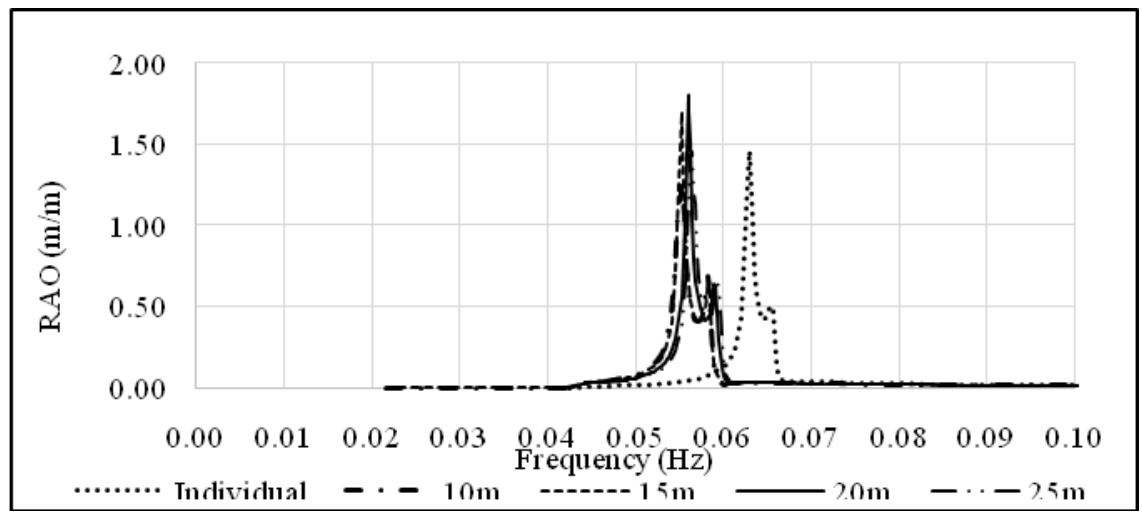

Fig. 6. Heave RAO vs wave frequency

\section{Summary}

A point absorber is one of the simplest and promising devices that can harness the wave energy at the ocean. Due to its relatively smaller dimension compared with another type of WEC, this device is most suitable to be deployed in an array where each isolated WEC interacts and altering the vicinity wave formation by absorbing, radiating and diffracting the wave. A simulation study was carried out to determine the effect of the separation distance between two WECs in an array configuration to the diffraction force and heave RAO. The simulation was initially considered an isolated WEC and preceded to the other simulation cases with various cases of the separation distance between two WECs. The separation distance of WEC is one of the most important parameters to be considered in designing an array of WECs. The result has shown that at a separation distance of $20 \mathrm{~m}$, the maximum heave RAO value is observed, whereby the optimum production of the wave energy is greatly dependent on the heave motion of the WEC. Meanwhile, the consideration of the diffraction force that shows an optimum separation distance of $10 \mathrm{~m}$ would be underestimated. This phenomenon can be explained by the destructive effect of the incoming waves that compensate each other which leads to a smaller impact of the wave interactions at $20 \mathrm{~m}$ distance. The findings are believed to encourage the usage of the point absorber in harnessing the wave energy in Malaysia, thus reducing the usage of nonrenewable energy. 
The support and encouragement provided by the Universiti Teknologi PETRONAS are gratefully acknowledged.

\section{References}

1. J. Kim, H. Kweon, W. Jeong, I. Cho, and H. Cho, Int. J. Nav. Archit. Ocean Eng., 7, 739-749 (2015)

2. H. Y. Chong and W. H. Lam, Renewable and Sustainable Energy Reviews, 23, 169178 (2013)

3. F. Behrouzi, M. Nakisa, A. Maimun, and Y. M. Ahmed, Renewable and Sustainable Energy Reviews, 62, 1270-1281 (2016)

4. N. H. Samrat, N. B. Ahmad, I. Choudhury, and Z. Taha, Power Engineering and Optimization Conference (PEOCO), 2014 IEEE 8th International, 127-132 (2014)

5. O. Ellabban, H. Abu-Rub, and F. Blaabjerg, Renewable and Sustainable Energy Reviews, 39, 748-764 (2014)

6. R. Kardooni, S. B. Yusoff, and F. B. Kari, Energy Policy, 88, 1-10 (2016)

7. E. W. E. Association, Pure power-wind energy targets for 2020 and 2030. Ewea, 2011.

8. T. Hooper, N. Beaumont, and C. Hattam, Renewable and Sustainable Energy Reviews, 70, 230-241 (2017)

9. M. N. Sahinkaya, A. R. Plummer, and B. Drew, Proceedings of the Institution of Mechanical Engineers, Part A: Journal of Power and Energy, 223, 887-902 (2009)

10. J.R. Nader, S.P. Zhu, and P. Cooper, Ocean Engineering, 88, 131-148 (2014)

11. A. Babarit, Renewable Energy, 58, 68-78 (2013)

12. B. Child and V. Venugopal, Proceedings of the 7th European Wave and Tidal Energy Conference, Porto, Portugal, (2007).

13. B. Bosma, "On the design, modeling, and testing of ocean wave energy converters," 2013.

14. S. K. Chakrabarti, Computational Mechanics Publications, (1987)

15. B. Borgarino, A. Babarit, and P. Ferrant, Ocean Engineering, 41, 79-88 (2012)

16. A. Babarit, Ocean Engineering, 37, 718-729 (2010)

17. L. Wang, J. Engström, M. Leijon, and J. Isberg, AIP Advances, 6 (2016) 